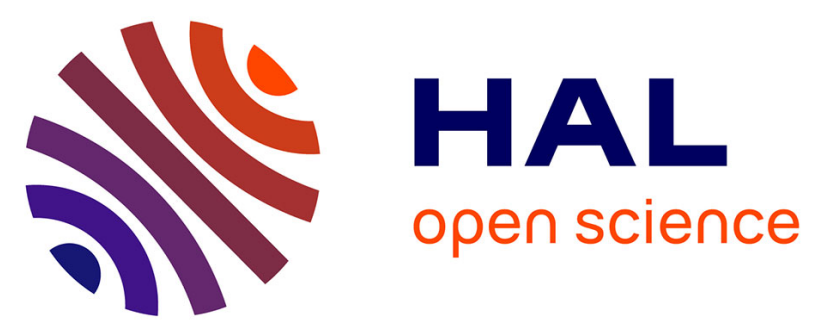

\title{
Quality of life in children with severe forms of idiopathic nephrotic syndrome in stable remission-A cross-sectional study
}

\author{
Aphaia Roussel, Jean-Daniel Delbet, Laurianne Micheland, Georges
}

Deschênes, Stéphane Decramer, Tim Ulinski

\section{To cite this version:}

Aphaia Roussel, Jean-Daniel Delbet, Laurianne Micheland, Georges Deschênes, Stéphane Decramer, et al.. Quality of life in children with severe forms of idiopathic nephrotic syndrome in stable remissionA cross-sectional study. Acta Paediatrica, 2019, 108 (12), pp.2267-2273. 10.1111/apa.14912 . hal02361199

\section{HAL Id: hal-02361199 \\ https://hal.sorbonne-universite.fr/hal-02361199}

Submitted on 29 Jun 2020

HAL is a multi-disciplinary open access archive for the deposit and dissemination of scientific research documents, whether they are published or not. The documents may come from teaching and research institutions in France or abroad, or from public or private research centers.
L'archive ouverte pluridisciplinaire HAL, est destinée au dépôt et à la diffusion de documents scientifiques de niveau recherche, publiés ou non, émanant des établissements d'enseignement et de recherche français ou étrangers, des laboratoires publics ou privés. 


\section{Quality of Life in Children With Severe Forms of Idiopathic Nephrotic Syndrome in Stable remission- A Cross-Sectional Study}

\section{Aphaia Roussel 1 , Jean-Daniel Delbet 1 , Laurianne Micheland 2 , Georges Deschênes}

3 , Stephane Decramer 4 , Tim Ulinski 15

1 Service de Néphrologie et Dialyse Pédiatrique, Hôpital Trousseau, APHP.6, and DHU i2b, Paris, France.

2 INSERM, UMR 1153, ECSTRA, Hôpital Saint-Louis, AP-HP, Paris, France.

3 Service de Néphrologie Pédiatrique, Hôpital Robert Debré, AP-HP, Paris, France.

4 Service de Néphrologie Pédiatrique, Hôpital Purpan, Toulouse, France.

5 Sorbonne Université, Paris, France.

\section{Abstract}

Introduction. Severe forms of idiopathic nephrotic syndrome (INS) require immunosuppressive therapy: oral treatment or intravenous therapy (rituximab, RTX). The main objective was to describe quality of life (QOL) in these specific patients.

Methods. Prospective, multicenter, observational study analysed QOL using a standardized questionnaire in children aged from 7 to 17 years old, with a steroid dependent or resistant INS in stable remission. The questionnaire consisted of 30 questions concerning physical and emotional well-being, self-esteem, family, friends, school, and disease resulting in a global score of 0 to 100 .

Results. 110 patients with a mean age of 11.6 years from three French pediatric nephrology centres were included. 71 patients had oral immunosuppressive treatment, 27 had RTX and 12 had both. $13.6 \%$ of patients had a steroid resistant INS. The mean number of relapses was 5.8. 78 patients answered the questionnaire. The global score in the whole study population was 74.7; 72.6 in the RTX group, 76.2 in the oral drugs group, $(p=0.49)$. The results of subdimension "School" were statistically lower in RTX group $(61.6 \pm 19.5)$ compared to oral drugs group $(71.4 \pm 16 ; \mathrm{p}=0.02)$.

Conclusion. QOL was satisfactory in 'difficult-to-treat' INS patients in stable remission on oral immunosuppressive or RTX treatment. 


\section{Abbreviations}

FRNS $=$ frequent resistant nephrotic syndrom

INS = Idiopathic nephrotic syndrom

OID $=$ Oral immunosuppressive drugs

PRO $=$ Patient Reported Outcome

PROQOLID = Patient Reported Outcome and Quality Of Life Instruments Database

PS $=$ Propensity score

$\mathrm{QOL}=$ Quality of life

RTX $=$ Rituximab

SDNS $=$ Steroid dependant nephrotic syndrom

SRNS $=$ Steroid resistant nephrotic syndrom

SSNS $=$ Steroid sensitive nephrotic syndrom 


\section{Introduction}

Idiopathic nephrotic syndrome (INS) is the most common glomerular disease in pediatric nephrology with a prevalence of about 16 cases per 100,000 children (1). It is associated with considerable morbidity and most patients present multiple relapses.

A large number of patients evolve to a frequent relapsing nephrotic syndrome (FRNS), a steroid-dependent nephrotic syndrome (SDNS), or, more rarely, a steroid-resistant nephrotic syndrome (SRNS). In these situations immunosuppressive drugs are recommended in order to reduce steroid exposure. Oral immunosuppressive drugs (OID) or rituximab (RTX) have shown efficacy concerning longterm disease control.

Among OID are calcineurine inhibitors $(2,3)$, levamisole $(4,5)$, and mycophenolate mofetil/ mycophenolic acid $(6,7)$. However, many patients become dependent on these drugs as disease activity is not reduced after treatment withdrawal.

As an alternative, rituximab, an anti-CD20 antibody which induces prolonged B cell depletion for several months, has shown similar efficacy as tacrolimus in SDNS patients $(8,9)$.

Patients' quality of life (QOL) might play a role in the treatment choice. It is difficult to perform a randomized controlled trial comparing QoL depending on treatment choice, but an observational cross sectional study can help to measure QoL in patients with 'difficult-totreat' nephrotic syndrome. Some studies measured QOL in children and adolescents with INS (10) (11), showing that chronic disease has an impact on some QOL dimensions.

QOL is a patient-reported outcome (PRO) and increasingly used as a primary endpoint in studies. The working group Mapi Research Trust promotes the use and development of PRO and has created the Patient Reported Outcome and Quality Of Life Instruments Database (PROQOLID). In clinical practice the objective of measuring QoL is to put focus on the patient rather than on pure disease related parameters. This may help on an individual basis to identify patients with a low QoL for whom a different treatment strategy might be used.

The current observational study evaluated the QoL in children diagnosed as having frequent relapsing, steroid dependent, or steroid resistant idiopathic nephrotic syndrome (INS) treated with different immunosuppressive treatment at a point of time.

\section{Methods}




\section{Study design}

We performed a prospective observational multicenter study, in three French pediatric centres (Armand Trousseau and Robert Debre hospitals in Paris and Purpan hospital in Toulouse), with an inclusion period of 7 months.

\section{Population}

Children were 7 to 17 years old with a diagnosis of INS as defined according to the international guidelines (International Society of Nephrology, (12)) and with a need for an immunosuppressive treatment for more than three months and stable disease (without relapses during the last three months) were included in the study. Severe INS is defined by a corticoresistance or corticodependance or frequent relapses. A high level of corticodependance was defined by relapses during steroidtherapy $>1 \mathrm{mg} / \mathrm{kg}$ every other day.

Non-inclusion criteria were as follows: patients with a secondary nephrotic syndrome, kidney transplantation or immunosuppressive treatment for other causes.

Treatment with OID could include mono- or bi-therapy and oral intake could be daily or twice daily. We did not report OID or steroid dosage.

RTX was given to achieve CD19+ B-cell depletion for 18 to 24 months. This treatment modality has been chosen, because of the low longterm remission rate after a single RTX course $(13,14)$. Rituximab dose was $375 \mathrm{mg} / \mathrm{m}^{2}$ intravenously during hospitalization, with a pre-therapeutic assessment and a pre-medication adapted to each child with a monthly B-cell monitoring. RTX was re-injected at each B cell recovery (CD19 count $>1 \%)$.

Patients with additional immunomodulatory treatments such as intravenous immunoglobulines were not included.

Patients with INS were identified using the national hospital discharge database according to diagnostic coding. The list of patients was provided by each of the three hospitals and the selection was made according to the inclusion and non-inclusion criteria.

\section{Interventions}


Details of all patients, including their age, gender, home address, type of INS, disease duration, number of relapses, weight and size, type of treatment and complications were obtained from the electronic patient file.

The Kindl ${ }^{\circledR}$ questionnaire was listed in PROQOLID (supplementary data) with a French version and adapted to the patients' age. It was previously used in several studies, especially for children with chronic diseases $(15-17)$. The $\mathrm{Kindl}^{\circledR}$ questionnaire consists of 30 questions grouped under their domains related to physical and emotional well-being, self-esteem, family, friends, school, and disease, resulting in a global score of 0 to 100 . The Kindl ${ }^{\circledR}$ total score was calculated as following:

(Sub-scale score - lowest possible score) / (possible range of raw score)*100. The higher the score, the better the QOL.

The Kindl ${ }^{\circledR}$ questionnaire was delivered to patients either by postal mail accompanied by a letter of information or during consultations in pediatric nephrology centers.

The questionnaire was systematically completed by the child.

\section{Endpoints}

The primary endpoint was the global QOL score of the Kindl ${ }^{\circledR}$ questionnaire.

The secondary endpoints were the sub-scores of the $\mathrm{Kindl}^{\circledR}$ questionnaire, and the global score and sub-scores in subgroups of patients (girls and boys, patients over and under 13 years old, patients with a disease duration less or more than five years and patients with a number of relapses less or more than five).

\section{Statistical analysis}

The characteristics of the population were described by mean, standard deviation (SD), median and interquartile range for quantitative data, and number and percentage for qualitative data.

The difference in endpoints between the means of the Kindl ${ }^{\circledR}$ scores was tested by Student test with a 0.05 significance level. 
To reduce bias, a method based on propensity score (PS) was used to estimate the average treatment effect on QOL. It was defined as the probability for a patient to be treated by either RTX or OID, based on individually observed covariates.

We selected as explanatory variables: age, sex, type of INS, number of relapses, disease duration, size, and weight. It is also necessary to include variables that can directly affect the primary endpoint, such as confounding factors like siblings, school type and home address.

To evaluate the average treatment effect on QOL we used the weighting method, adapted to the size of our population (18).

All analyses were performed using $\mathrm{R}$ version 3.3.3. All p-values were 2-sided with a significance threshold of $\mathrm{p}<0.05$.

\section{Autorization}

Data were collected by a pediatric nephrology resident and analysed in Trousseau hospital.

The use of this questionnaire was obtained with permission from the Kindl ${ }^{\circledR}$ group, Collaboration Form, Hamburg UKE.

The final protocol, amendments, and informed consent documentation were approved by an independent ethics committee. All patients provided written informed consent.

\section{Results}

\section{Study population}

110 patients were included: 71 on oral drugs, 27 on RTX and 12 with both treatments. These 12 were excluded from the comparison concerning treatment modalities.

The characteristics of age, gender, type of INS, number of relapses, disease duration, size and weight are summarized in Table 1.

Mean age was $12.1 \pm 2.8$ years old for girls, and $11.3 \pm 3.1$ for boys.

Among patients treated with an OID, 13 patients required bi-therapy to achieve relapse free disease. Since disease onset, the number of therapeutic changes varied from 0 to 7 . The majority of patients had less than 3 changes.

Patients treated with RTX had a first infusion after a mean disease duration of 2.9 years $($ median $=2.5$ years, Q1-Q3 $=[1.2-6.9])$. The mean number of RTX infusions was $4.2 \pm 3$ $(\mathrm{Q} 1-\mathrm{Q} 3=[2-5]$ Min-Max $=[1-15])$. 
Side effects were reported in 55\% of patients in OID (Figure 1) groups and $48 \%$ in RTX group (Figure 2).

\section{Primary outcome}

78 patients completed the questionnaire: 48 in the OID group, 25 in the RTX group and 5 with both treatments. These 5 were excluded from the analysis. Mean global score before the use of PS was $75.5 \pm 12.1$ in the total population and it was $75.4 \pm 10.8$ in the OID group and $75.6 \pm 15.2$ in the RTX group.

After the use of PS it was $74.7 \pm 12.1 ; 72.6 \pm 15.2$ in the RTX group, $76.2 \pm 10.8$ in the oral drugs group, $(\mathrm{p}=0.49)$.

\section{Secondary endpoints}

For 6 of the 7 dimensions of the $\operatorname{Kindl}^{\circledR}$ questionnaire sub-scales, there was no significant difference between the two groups. The "School" sub-dimension was the only one with a significant difference observed after use of the PS $(p=0.033)$. This difference showed a better score for patients in the OID group (Figure 3a et b).

QOL was measured for four sub-groups and without adjustment to other variables.

The results for the global score were summarized in Figure 4.

It appears that girls have a better QOL with RTX treatment. However, there was no difference according to the age group. The global score was not different depending on disease duration or relapse number.

\section{Discussion}

This study analyzes QOL in patients with severe forms of INS with two different treatment strategies, intravenous and oral immunosuppression.

Patients with SDNS and SRNS had a satisfactory QOL which was close to the QOL of children without a chronic disease.

A recent study from India showed that children with INS had a better QOL than patients with other chronic diseases, except for the "education" dimension (19). The patients included in this study had different degrees of INS severity ranging from patients with a first episode to 
multidrug resistant INS. It has to be considered that QOL can be different during relapse (10), but all patients were in stable remission at the time of the study. The participation rate in our study was satisfactory (71\%), but patients who did not respond might have had a lower QOL. However, there was no difference between these patients and the others regarding their disease severity parameters.

We did not find any significant difference in QOL depending on the treatment (OID or RTX) for the global QOL score, even if a precise comparison was not possible. RTX treated patients had multiple relapses despite different oral drugs before the introduction of RTX. Their disease activity is initially higher in order to justify RTX treatment. Therefore, a good quality of life in RTX treated patients is encouraging. Individual adaptation of the treatment strategy is mandatory, but no specific patient group (age or gender) seems to be at risk for low QOL. RTX treated patients had a more severe disease as their relapse number was almost twice as high as in patients on OID. However, RTX achieves disease control without daily medication, but requires a short hospitalization for the RTX infusions. Disease control might therefore be better due to absence of non-compliance. Adherence problems are well known in chronic diseases and not specific to pediatric nephrology (20). Among the patients who did not respond to the questionnaire, the majority were treated with OID. The consequences on the QOL of these missing data cannot be analyzed, despite an overall good participation rate.

Regarding the school dimension, the QOL was lower in the RTX group. This may be explained by the repeated short hospitalizations for RTX infusions or the monthly B cell monitoring. The impact of the lower "school" QOL should be further explored regarding school results in patients on RTX or OID in future controlled studies. A clear comparison of these patient groups would have been possible only in a randomized controlled trial, despite the use of the propensity score.

There were more adolescent girls than adolescent boys (median age 13 years for girls and 10.7 years for boys). However, neither age nor disease duration, or relapse number seemed to be associated with a difference in QOL. These unadjusted results should be considered with caution, especially because of a previous study that showed an impact of disease duration on QOL (21). 
The comparison of our study with other published studies was difficult. The patients in our study were in stable remission on long-term immunosuppressive treatment. Others have analyzed QOL as a secondary objective. One randomized controlled trial compared the QOL in Crohn's disease between two oral treatments (22) which differed in their daily intake (1 versus 2 with a better QOL reported for 1 treatment dose).

The QOL questionnaire chosen for this study was validated, standardized and already used previously. It explored important dimensions of QOL and was adapted to chronic diseases. Nevertheless, it was not a specific INS questionnaire.

There was an uncontrolled measurement bias as some children received the questionnaire by mail. The conditions for replying to the questionnaire could therefore differ from the others, possibly with the presence of the parents who could influence the answers. We deliberately chose not to question parents about the QOL of their child, as they are often the cause of undervaluation (23).

One of the perspectives would be to compare QOL in children on oral treatment and on RTX treatment by repeated QOL measurements, before, during, and after treatment.

In conclusion, QOL was satisfactory in patients with severe INS on RTX or OID. The QOL seems to be good in both groups; however, patients on RTX had a lower "school QOL". QOL questionnaires may help to find the best individualized strategy for each patient and should be integrated into the management of the patient and his/her family in addition to classical disease related parameters, with regular reassessment and prevention of factors that may aggravate it. 


\section{Bibliography}

1. Eddy AA, Symons JM. Nephrotic syndrome in childhood. Lancet Lond Engl. 23 août 2003;362(9384):629-39.

2. Dudzik B, Kaczmarczyk I, Radziszewski A, Sułowicz W. [Use of Cyclosporine A and new immunosuppressive drugs in the therapy of glomerulonephritis]. Przegl Lek. 2001;58(7-8):798-804.

3. Gulati S, Prasad N, Sharma RK, Kumar A, Gupta A, Baburaj VP. Tacrolimus: a new therapy for steroid-resistant nephrotic syndrome in children. Nephrol Dial Transplant Off Publ Eur Dial Transpl Assoc - Eur Ren Assoc. mars 2008;23(3):910-3.

4. Levamisole for corticosteroid-dependent nephrotic syndrome in childhood. British Association for Paediatric Nephrology. Lancet Lond Engl. 29 juin 1991;337(8757):1555-7.

5. Donia AF, Amer GM, Ahmed HA, Gazareen SH, Moustafa FE, Shoeib AA, et al. Levamisole: adjunctive therapy in steroid dependent minimal change nephrotic children. Pediatr Nephrol Berl Ger. mai 2002;17(5):355-8.

6. Barletta G-M, Smoyer WE, Bunchman TE, Flynn JT, Kershaw DB. Use of mycophenolate mofetil in steroid-dependent and -resistant nephrotic syndrome. Pediatr Nephrol Berl Ger. août 2003;18(8):833-7.

7. Novak I, Frank R, Vento S, Vergara M, Gauthier B, Trachtman H. Efficacy of mycophenolate mofetil in pediatric patients with steroid-dependent nephrotic syndrome. Pediatr Nephrol Berl Ger. sept 2005;20(9):1265-8.

8. Ravani P, Magnasco A, Edefonti A, Murer L, Rossi R, Ghio L, et al. Short-term effects of rituximab in children with steroid- and calcineurin-dependent nephrotic syndrome: a randomized controlled trial. Clin J Am Soc Nephrol CJASN. juin 2011;6(6):1308-15. 9. Iijima K, Sako M, Nozu K, Mori R, Tuchida N, Kamei K, et al. Rituximab for childhood-onset, complicated, frequently relapsing nephrotic syndrome or steroid-dependent nephrotic syndrome: a multicentre, double-blind, randomised, placebo-controlled trial. Lancet Lond Engl. 4 oct 2014;384(9950):1273-81.

10. Gipson DS, Selewski DT, Massengill SF, Wickman L, Messer KL, Herreshoff E, et al. Gaining the PROMIS perspective from children with nephrotic syndrome: a Midwest pediatric nephrology consortium study. Health Qual Life Outcomes. 4 mars 2013;11:30.

11. Rüth E-M, Landolt MA, Neuhaus TJ, Kemper MJ. Health-related quality of life and psychosocial adjustment in steroid-sensitive nephrotic syndrome. J Pediatr. déc 2004;145(6): 778-83.

12. Official journal of the international society of nephrology. KDIGO Guideline. 2012;

13. Sellier-Leclerc A-L, Macher M-A, Loirat C, Guérin V, Watier H, Peuchmaur M, et al. Rituximab efficiency in children with steroid-dependent nephrotic syndrome. Pediatr Nephrol Berl Ger. juin 2010;25(6):1109-15.

14. Sellier-Leclerc A-L, Baudouin V, Kwon T, Macher M-A, Guerin V, Lapillonne H, et al. Rituximab in steroid-dependent idiopathic nephrotic syndrome in childhood--follow-up after CD19 recovery. Nephrol Dial Transplant. 1 mars 2012;27(3):1083-9.

15. Stahl-Pehe A, Straßburger K, Castillo K, Bächle C, Holl RW, Lange K, et al. Quality of life in intensively treated youths with early-onset type 1 diabetes: a population-based survey. Pediatr Diabetes. sept 2014;15(6):436-43.

16. Werkstetter KJ, Ullrich J, Schatz SB, Prell C, Koletzko B, Koletzko S. Lean body 
mass, physical activity and quality of life in paediatric patients with inflammatory bowel disease and in healthy controls. J Crohns Colitis. juill 2012;6(6):665-73.

17. Wehmeier PM, Schacht A, Dittmann RW, Helsberg K, Schneider-Fresenius C, Lehmann $\mathrm{M}$, et al. Effect of atomoxetine on quality of life and family burden: results from a randomized, placebo-controlled, double-blind study in children and adolescents with ADHD and comorbid oppositional defiant or conduct disorder. Qual Life Res Int J Qual Life Asp Treat Care Rehabil. juin 2011;20(5):691-702.

18. Pirracchio R, Resche-Rigon M, Chevret S. Evaluation of the propensity score methods for estimating marginal odds ratios in case of small sample size. BMC Med Res Methodol. 30 mai 2012;12:70.

19. Agrawal S, Krishnamurthy S, Naik BN. Assessment of quality of life in children with nephrotic syndrome at a teaching hospital in South India. Saudi J Kidney Dis Transplant Off Publ Saudi Cent Organ Transplant Saudi Arab. juin 2017;28(3):593-8.

20. Jacquin P, Levine M. [Poor adherence in chronic conditions during adolescence: understand in order to act]. Arch Pediatr Organe Off Soc Francaise Pediatr. janv 2008;15(1): 89-94.

21. Selewski DT, Troost JP, Massengill SF, Gbadegesin RA, Greenbaum LA, Shatat IF, et al. The impact of disease duration on quality of life in children with nephrotic syndrome: a Midwest Pediatric Nephrology Consortium study. Pediatr Nephrol Berl Ger. sept 2015;30(9): 1467-76.

22. Thomsen OO, Cortot A, Jewell D, Wright JP, Winter T, Veloso FT, et al. Budesonide and mesalazine in active Crohn's disease: a comparison of the effects on quality of life. Am J Gastroenterol. mars 2002;97(3):649-53.

23. Dodson JL, Gerson AC, Hsiao C-J, Kaskel FJ, Weiss RA, Furth SL. Parent perspectives of health related quality of life in adolescents with chronic kidney disease due to underlying urological disorders: an assessment using the Child Health Questionnaire-Parent Form 50. J Urol. oct 2008;180(4 Suppl):1700-4; discussion 1704. 